\title{
No difference existed in developmental outcomes at 3 years of age between early or delayed tympanostomy for otitis media
}

\author{
Paradise JL, Feldman HM, Campbell TF, et al. Effect of early or delayed insertion of tympanostomy tubes for persistent otitis \\ media on developmental outcomes at the age of three years. N Engl J Med 2001 Apr 19;344:1179-87. \\ QUESTION: In young children with persistent otitis media with effusion (OME), does \\ prompt insertion of tympanostomy tubes protect against or minimise subsequent \\ developmental impairment at 3 years more than delayed insertion?
}

\section{Design}

Randomised (allocation concealed*), blinded (outcome assessors),* controlled trial with follow up to 3 years of age.

\section{Setting}

2 hospitals and 6 private paediatric group practices in and around Pittsburgh, Pennsylvania, USA.

\section{Patients}

Of 6350 children enrolled by 2 months of age, 429 children (mean age $15 \mathrm{mo}, 57 \%$ boys) in whom persistent OME developed by 3 years of age participated. Exclusion criteria included birth weight $<2270 \mathrm{~g}$, small size for gestational age, history of neonatal asphyxia or other serious illness, major congenital malformation, and multiple births. 94\% completed the study.

Sources of funding:

National Institute for Child Health and Human Development; Agency for Healthcare Research and Quality; SmithKline Beecham Laboratories; Pfizer.

For correspondence: DrJ L Paradise, Children's Hospital of Pittsburgh, 3705 Fifth Avenue, Pittsburgh, PA 15213-2538, USA.

$\mathrm{Fax}+1412692$ 8012 .

A modified version of this abstract also appears in Evidence-Based Nursing.

\section{Intervention}

216 children were allocated to early (defined as "as soon as possible") insertion of tympanostomy tubes, and 213 were allocated to late (defined as up to 9 mo later if effusion persisted) insertion of tympanostomy tubes (66 of the 196 children tested [34\%] received tubes by $3 \mathrm{y}$ of age).

\section{Main outcome measures}

Developmental outcomes, including speech, language, cognition, and psychosocial development (parenting stress and child behaviour) at 3 years of age.

\section{Main results}

At 3 years of age, no statistically significant differences existed between the treatment groups for any of the outcomes (table).

Differences (early treatment group minus late treatment group) in the mean scores of developmental outcomes at 3 yearst

\begin{tabular}{|c|c|c|c|c|}
\hline Outcomes & Scale & Early $\boldsymbol{v}$ late & $\begin{array}{l}\text { Difference in mean } \\
\text { score between groups } \\
(95 \% \mathrm{Cl})\end{array}$ & $\begin{array}{l}\text { Normative } \\
\text { data (SD) }\end{array}$ \\
\hline Speech & PCC-R & $85 v 86$ & $-1(-2.1$ to 0.7$)$ & 一 \\
\hline \multirow[t]{3}{*}{ Language } & PPVT-R & $92 \vee 92$ & 0 (-2.8 to 2.8$)$ & $100(15)$ \\
\hline & NDW & $124 v 126$ & $-2(-7.6$ to 4.8$)$ & - \\
\hline & MLUM & $2.7 v 2.8$ & $-0.1(-0.2$ to 0.0$)$ & - \\
\hline Cognition & $\mathrm{MGCl}$ & $99 \vee 101$ & $-2(-4.1$ to 1.1$)$ & $100(15)$ \\
\hline Parenting stress & Total stress & $66 \vee 68$ & $-2(-5.3$ to 2.3$)$ & $71(15)$ \\
\hline Child behaviour & Total problems & $50 \vee 49$ & $1(-0.6$ to 3.4$)$ & $50(10)$ \\
\hline
\end{tabular}

\section{Conclusion}

In young children with persistent otitis media with effusion within the durations studied, prompt insertion of tympanostomy tubes did not improve developmental outcomes at 3 years of age.

*See glossary.

\section{COMMENTARY}

This trial by Paradise $e t$ al is methodologically sound by prevailing standards. Its presentation uses the standard deviation, which is a generally understandable metric of magnitude. Among other virtues, this approach helps to clarify that the treatment effects on the particular sample are truly null.

Under caveats, the authors acknowledge that more positive results, both on developmental sequelae of OME and on remediation by ventilation tube treatment, could have occurred with older or with more stringently defined patients. In the delayed treatment control group, 117 children (64\%) had effusion for more than half the time. Let us take this proportion as typical for all the entrants. Such a subgroup of children might show benefit in a future trial. The inclusion criteria also led to most children having only unilateral effusion. In many countries, such children would not be considered for treatment. The surveillance and intervention implied by the entry criterion are comparable to those in a trial by Rovers et al. ${ }^{1}$ Together, these 2 null trials indicate that treating near-normal patients for a mild non-progressive condition is usually neither wise nor cost effective. Despite the expectations of some US clinicians, null results were likely because of the very high spontaneous remission rate at this age for fluid in the ears and the dilution of treatment effects according to how developmentally "downstream" the measures considered are (eg, language development).

In conclusion, some children with OME may benefit from tube insertion. Unfortunately, the data reported from this trial do not allow us to delimit which ones. Nevertheless, the high intervention rates in some countries are challenged, and more secure evidence of severity, persistence, and impact of disease, beyond its mere presence, should inform the decision to place tubes. Clinical policies in those countries will probably become more conservative.

Martin Burton, MA, DM Radcliffe Infirmary Oxford, UK

Mark Haggard, $\mathrm{PhD}$ MRC Institute of Hearing Research Nottingham, UK

1 Rovers MM, Straatman H, Ingels K, et al. The effect of ventilation tubes versus watchful waiting on language development in infants with persistent OME: a randomised trial. Pediatrics 2000;106:e42. 